\title{
Health of Urban Women with Respect of HIV Infection: A Case Study in Dakshina Kannada
}

\author{
Laveena D’Mello ${ }^{1}$ \& Govindaraju B. M. $^{2}$ \\ ${ }^{1}$ Senior Lecturer, Social Work Department, Srinivas Institute of Management Studies, \\ Mangalore-575001, India \\ ${ }^{2}$ Asst. Professor, Dept. of Sociology, Mangalore University, Karnataka, India. \\ E-mail: lavynoronha@gmail.com
}

Type of the Paper: Research Article.

Type of Review: Peer Reviewed.

Indexed In: OpenAIRE.

DOI: http://dx.doi.org/10.5281/zenodo.579648.

Google Scholar Citation: $\underline{\text { IJHSP }}$

\section{How to Cite this Paper:}

D’Mello, Laveena., \& B. M., Govindaraju. (2017). Health of Urban Women with Respect of HIV Infection: A Case Study in Dakshina Kannada. International Journal of Health

Sciences and Pharmacy (IJHSP), 1(1), 21-28.

DOI: http://dx.doi.org/10.5281/zenodo.579648.

International Journal of Health Sciences and Pharmacy (IJHSP)

A Refereed International Journal of Srinivas University, India.

(C) With Authors.

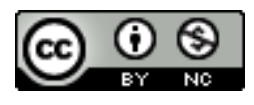

This work is licensed under a Creative Commons Attribution-Non Commercial 4.0 International License subject to proper citation to the publication source of the work.

Disclaimer: The scholarly papers as reviewed and published by the Srinivas Publications (S.P.), India are the views and opinions of their respective authors and are not the views or opinions of the SP. The SP disclaims of any harm or loss caused due to the published content to any party. 


\title{
Health of Urban Women with Respect of HIV Infection: A Case Study in Dakshina Kannada
}

\author{
Laveena D’Mello ${ }^{1}$ \& Govindaraju B. M. $^{2}$ \\ ${ }^{1}$ Senior Lecturer, Social Work Department, Srinivas Institute of Management Studies, \\ Mangalore-575001, India \\ ${ }^{2}$ Asst. Professor, Dept. of Sociology, Mangalore University, Karnataka, India. \\ E-mail: lavynoronha@gmail.com
}

\begin{abstract}
In Human Immuno-deficiency Virus and Acquired Immuno-Deficiency Syndrome (HIV/AIDS), the HIV virus attacks the immune system, which defends the human body against pathogens. When there is balance against the immune system, the people living with HIV/AIDS (PLHA) become more susceptible to opportunistic infections (OIs). With the bodies immune system is not capable of defending itself against Opportunistic Infections, the PLHA ultimately submit to them. In developed countries, the cost of antiretroviral (ARVs) has been borne completely by the state; as a result, there has been a decrease in the number of deaths on account of HIV in the past 15 years. On the other hand, the number of deaths in developing countries due to HIV continues. In this paper, the researchers have made an attempt to examine the status of health of women in urban areas with respect to HIV infection. With this specific aim tried to know the reasons for the HIV/AIDs infection and its effect, consequence on women health particularly. By adopting field survey, interview and case studies methods, 50 samples have been taken and analyzed them systematically.
\end{abstract}

Keywords: HIV/AIDS, People Living with HIV/AIDS (PLHA), Opportunistic Infections (OIs) and Antiretroviral (ARVs).

\section{INTRODUCTION :}

Health is an essential input for the development of human resources and the quality of life and in turn the social and economic development of the nation. Improvement in health status of the population has been regarded as an index of social development. Moreover, health is regarded as a priority for sustained development interventions at the individual, community and national levels. The health of a country's female population has profound implications for the health and education of children and the economic well-being of households, as well as for the women themselves. Acquired Immuno deficiency Syndrome (AIDS) emerged as the most dreaded disease of the century. This is dreaded not because of the fact that death is certain, but it is also due to the stigma and social ostracism that is attached to its very name. AIDS continues to be a major concern of research, which requires broad ranging structural analysis of the overall health care sector as well as the social, political and economical forces that influence its shape and content both in the western world and in the developing countries.

\section{HIV/ AIDS AND WOMEN :}

The AIDS epidemic has had a unique impact on women, has been exacerbated by their role within society and their biological vulnerability to HIV infection. Women suffer countless disadvantages compared with men. Though the "feminization" of the pandemic is more apparent in Saharan Africa, the HIV infection rate among women in India is also steadily rising. The first HIV/AIDS case in India was identified in Chennai, the capital of Tamil Nadu state, in 1986. Twenty-four years later, 2.4 million Indians are HIV positive, 
according to an estimate from the National HIV Sentinel Surveillance (UNGASS. 2010). Among them 39\% (9.3 Lakh) of HIV-positive Indians arc women. New infections in females are occurring faster than in males. HIV infected women have the potential for transmission to their infants. The average HIV prevalence among women attending antenatal clinics in India is $0.48 \%$ [2-3].

AIDS affects the poorest, the most vulnerable, and the most uneducated. And women often constitute the poorest of the poor, the most vulnerable due to their low status and more likely to be illiterate than men. In India, where 90 percent of female infections occur within marriage, women who stand up to their husbands risk violence-and those who get infected by their husbands are often shunned by their families. Lacking other skills, they may survive by selling sex - which, of course, spreads the disease further. According to (UNAIDS, 2010) sexual intercourse is the primary mode of HIV transmission in India, accounting for about 95 per cent of new HIV infections [9,11-12].

More than 90 per cent of infected women acquired the virus from their husbands or intimate partners. In most cases, women are at an increased risk not due to their own sexual behavior, but because their partners are IDU's (Injecting drug users) or also having FSW's (Female Sex Workers) or MSM (Men having sex with Men) as other sex partners. Women are frequently forced to tolerate abuse, violence and infidelity from their husbands (Soloman, et al, 2003) [4]. When they engage in sex, their lack of knowledge about their own sexual health, ignorance about their regular partner's and the continued culture of silence make them unable to negotiate safer sex practices. Since sexual contact with their husbands is the only risk factor for most married women, it is likely that these women were infected by their husbands (Gangakhedkar, et al, 1997) [2].

\section{VULNERABILITY IN WOMEN :}

Socio-cultural, Economic and Biological factors make women and girls more vulnerable to HIV and AIDS. In India, the low status of women, poverty, early marriage, trafficking, sex-work, migration, lack of education and gender discrimination are some of the factors responsible for increasing the vulnerability of women and girls to HIV infection. The HIV virus is more easily transmitted from men to women than from women to men. Male-tofemale transmission during sex is about twice as likely as female to-male transmission. Biologically, women appear to be susceptible to HIV infection. Gender inequality and poverty are responsible for the spread as well as disproportionate impact of HIV and AIDS on women [3].

Most women diagnosed with HIV infection are of child bearing age between the ages of 16 and 44 years. These women must make a series of complex decisions concerning contraception, pregnancy and abortion. Although little is known about how women living with HIV/AIDS make such decisions, the decision to have a baby is likely influenced by the interrelation of intrapersonal factors, family influences and social pressures. Numerous psychological and economic obstacles may prevent these women from seeking healthcare. Women with HIV and AIDS are likely to suffer additional burden of stigma, discrimination and marginalization. Often, women are blamed for her husband and/or child falling sick, suspected of infidelity by the family and society leading to rejection and expulsion by the family and community at large. Also, women are often first to be tested for HIV during pregnancy and hence blamed for having HIV, even though their male partners could be the true source of infection (UNICEF, 2005) [11]. When women get HIV, they often endure greater hardship than men. They sometimes lack rights to property, inheritance and child custody and suffer greater stigma. As caregivers, particularly in areas of poor public services, women have less time for income generation and productive tasks. A woman who becomes a widow is often thrown out of her house and is often denied her share in the husband's property and is likely to face isolation and discrimination from the family members. The subordinate status of women in the family and in society makes them more vulnerable to infection. Care-related costs can push the family further into poverty. AIDS, women and poverty are inextricably linked. The need to accelerate the response for women and AIDS is thus urgent. The burden of HIV disease 
among women in the developing world has been acquired heterosexually (i.e. from man to woman). This is due to HIV infection is transmitted more effectively, sexually, from men to women, lack of education and illiteracy among women, cultural beliefs regarding the role of women in the family and lack of economic power in the women. All the above factors influence the relative vulnerability of women, and decrease their access to means of prevention and support in the face of HIV/AIDS.

\section{REASONS FOR INFECTION :}

HIV provides the key to understanding the source of women's vulnerability to HIV infections. The HIV epidemic has taken advantage of the social, economic and cultural subordination of women, and has translated it into a death sentence. There are various factors that make an Indian woman not only more prone to HIV infection, but also less likely to seek medical attention. And they are [1] : Infection after marriage: In the developing countries nearly all HIV infection reported among women have been acquired heterosexually. Majority of the Indian women have been infected not through their own behaviour but through that of their husbands. An Indian woman's greatest risk of HIV infection might be her husband. 92\% of the Women got infection after their marriage [2,3]. Age of marriage: Culturally, initiation to sexual intercourse begins several years earlier for females than for males. $96 \%$ of the respondents are married and out of this, $68 \%$ of the respondents are married below 24 years. Many women are still in their mid-teens when they marry. Often women get married to much older men, who are more sexually experienced. Therefore, there are more chances for women to get HIV infected, from a husband, who might be indulging in sexual activities outside marriage [6]. Marriage is compulsory: There is no say to women regarding her life decision marry or not to marry? At what age she should marry?

She also does not enjoy the freedom to choose whether to become a mother, or to protect the life of an unborn child from forced abortion. Force from the family is making them vulnerable to HIV problem along with other family problems. In a marriage, women lack control over their lives, forget alone over their husbands' life outside the marriage. Extramarital relationships, intravenous drug abuse, and bisexual behaviour on the part of the husband are possible routes for entry of the virus into the marital union. For these women, sexual intercourse is not a question of choice, but rather a question of survival. The wife has hardly any say in when to have sexual intercourse, or how to protect herself from HIV infection, if the husband is infected. 96\% of the respondents are married and it is clear how marriage is compulsory in our society. Limited knowledge on Health Education and care: Women are expected to have children immediately after their marriage. They are looked upon as child bearers. In the sociological division of labours, they have much greater obligations and responsibilities towards their children and home. There is limited access to education, awareness and information. There is lack of financial resources to pay for the use of health care facilities. $48 \%$ of the respondents are illiterate or have primary level education and did not know about HIV. Ms. Ramani, illiterate working as cooli at construction site, came to know her husband is detected as HIV positive, she told everyone in the neighbourhood, and due to this she as to face stigma. They have sent both of them to go to their native and not to come back. This shows Ms. Ramani's ignorance about the disease.

First detection in Women: It is an unfortunate reality that when the first case of HIV/AIDS is identified within a family, when women will go for check-up during her pregnancy, the blame is most often attributed to the woman, even if the evidence contradicts this. There is fear that her family, because of her perceived past behaviour, will abandon her. She is forced to keep quiet and she is not in a position to argue her case. The stigma and discrimination associated with this disease, thus, often rests with woman. $36 \%$ of the respondent found first that they are infected, $12 \%$ when their children are symptomatic, 52\% after their husband's death or when their husbands were sick [10].

Hidden status of Husband: Risk Behaviour of the husband or the symptomatic husband will hide the situation with wife. By the time he 
comes to know his status he had already remitted it to his family, especially his wife and children. If women are not getting any support from the family, HIV positive women feel extremely lonely and isolated. Fear of social stigma compels them to keep the condition secret. They are afraid of being abandoned by family, friends and the community. $52 \%$ of the respondents were come to know their status after the death or symptomatic was very angry with them. But reaction was varied from the person to person. Dependent women accepted it easily but the $12 \%$ who were financially sound left the home and stayed separately [10].

Late detection: Indian women are often unaware of their HIV positive status, or, they may be the last in their family to know their diagnosis, due to the power hierarchy in the family structure. Some women discover that they are HIV positive by accident, usually after the husband or the child is found to be symptomatic with an HIV related disease. The women will then be dealing with two crises, that of illness of her husband or child, or both as well as her own illness. Researcher found that Husbands death due to various reasons like alcoholism, cancer or Cardio arrest made them not to know their status. But 34\% came to know only after few years of their husband's death. Then they had problem to accept the status later when they detected HIV positive.

Unfaithfulness: Women have to bare unfaithfulness of Husband before marriage, during her delivery, or after the birth of children. She as to deal emotionally with her husband's unfaithfulness when the first child is negative and second child is positive. She also have to undergo the situation when grown up children are negative and at her old age she as to undergo this trauma. If she passes the illness to her children, she feels angry towards the husband and herself that she is the cause of illness of her children. $82 \%$ of the respondents expressed they are the victims of their husbands unfaithfulness before and after their marriage. Ms. Radha, used to stay in Mumbai, came to settle in Mangalore after her delivery. It was difficult for her to take care of young three children in Mumbai, so she started staying with mother with the consent of her husband. He used to visit her regularly. Her three kids were negative and only she is positive. Her husband died due to alcohol she says. Now she is 58 years, all her children are settled. And she expresses that her husband is unfaithful to her and gave disease to her and she as to bare it. Ms. Malini says that her husband was very faithful to her. He never had any affair or doubt about her husband's character. Both are positive stay separately in rented house. She things her husband had exposure to HIV before marriage and he was also ignore about it. Both stay together with harmony, supporting each other with restricted confidentially and are on ART with asymptomatic $[5,8]$.

Subordinate Role: In India, most women have to play a subordinate role in the family. They are not independent to take any decision in the family. For any minor decision they are dependent on their husbands and his family. Unemployed ladies are totally depending for food, clothing, shelter and money on their husband. It is usually the male partner, who usually controls the financial matters at home. As a result of this, abstinence, faithfulness on man's part, which has now become the mainstay of protection against HIV disease, is totally the man's prerogative. Ms. Rukya, 45 years widow had no support, landed up in care and support centre. Ms. Jameela, 38 years old lady after she is symptomatic came to stay with her father. Her husband deserted her and the children. Her husband was positive. Ms. Rukya has the hope saying 'even my husband leaves me; my father will not leave me'. He will take care of me and my children.

Burden and Bereavement: From the time of her birth, the Indian psyche considers the female child, a burden, initially to her family, and later on, to her husband's family. The main aim of her biological family is to marry her off, as quickly as possible in order to ease this burden. She is usually given minimum education and care before marriage. After marriage, in case of the husband's death his property, provident fund (if any), remains with the husband's family and in many cases, the wife goes back to her own family, where she continues to be a financial and emotional burden. Many such women are also forced into prostitution for a living. Ms. Laxmi, Widow of 46 years old along with negative son of 10 years, after her husband's death came to stay 
with brother, where she as to bare stigma. With the interference of the NGO and support group she was helped to have a separate room attached to her brother's family, where she got a separate door number and all the facilities from the NGO. Ms. Rathna, 25 years old stay with her parents. Her younger sister got married. Ratna is positive and her husband died due to HIV. She does not have children. After her husband's death she came back to her mother's place. Her sister married and she is happily leading her life with her husband and a kid. Now she feels she also wanted to settle in life but lack of daring to settle again and says all have good life my sister and my friends. But why it is for me? Who will marry me? My life is over and lost all hopes in life. Pregnancy: Women are considered to be the potential bearer of sons. It is a persistent Indian belief that the sons are the ones, who will grow up, and earn and look after the old parents while daughters are a burden, who will have to be given away in the marriage. Even if a woman is HIV positive, she may be under pressure to produce a son, at risk to her own life and future.

\section{CHALLENGES AND HEALTH CONDITIONS :}

It has been found that the impact of HIV and AIDS reaches far beyond the health sector with severe economic and social consequences and the impact is much more severe on women than on men. Women and girls seem to bear the brunt of the pandemic in many ways and the disease disproportionately affects them psychologically, socially and economically. Attempts to limit the spread of HIV infection in women through education for men such as partner reduction, condom use and early detection and treatment of STDs have been limited. All currently available methods to prevent sexual transmission of HIV to a woman require male co-operation, which is not always forthcoming. One could speculate that the age gap between younger women and their sexual partners is likely to worsen this trend. Therefore, developing an HIV control technology within the personal control of women should be the global priority. Enhancement of the level of awareness among young women and men needs to be given top priority by adopting diverse innovative approaches. However, organization of group based educational sessions for young women can be possible only through creating a conducive and enabling environment by involving local advocacy groups, senior males and females in the communities. Programme design should not ignore the differential power between men and women, especially when negotiating for safe behaviors. By making women and men working together can do more to address on these issues [12].

Apart from empowering women with information on the prevention of disease, they should also be given adequate training to act as peers and educators to the risk groups. Women counselors, attending on target populations, school and college students, pre- marital youth, housewives, working and non- working women, women of low socio- economic status and media watchers, should be encouraged and provided sufficient back- up. Pregnant women should be provided access to other HIV prevention and treatment services (e.g., counseling, drug-treatment and partnernotification services) as needed. Eliminating vertical transmission requires far greater, and more rapid, advances to increase coverage and administer more effective regimens. Enhanced efforts are required to integrate HIV testing into antenatal services and services to prevent mother to- child transmission need to be more closely linked to sexual and reproductive health care. The healthcare providers should ensure that all pregnant women are counseled and encouraged to be tested for HIV infection, to allow women to know their infection status both for their own health and to reduce the risk for prenatal HIV transmission. Counseling should include information regarding the risk for HIV infection associated with sexual activity and injecting-drug use, the risk for transmission to the woman's infant if she is infected, and the availability of therapy to reduce this risk. HIV counseling, including any written materials, should be linguistically, culturally, educationally, and age appropriate for individual patients.

Communities, in particular women living with HIV, should be enabled and empowered to support women and their families to access the HIV prevention, treatment and care that they need. Women must share a common political concern and recognition of their mutual 
vulnerability vis-a-vis the disease if they are to mobilize effectively for HIVIAIDS prevention. Program areas must include promoting empowerment of women through women's collectives and income generating cooperatives. A gender- specific approach aimed at benefiting women is being incorporated into almost all AIDS strategies now. It cannot be over- stressed that most of the strategies which claim to benefit women are yet to gain momentum. Developing countries, including India, have not overcome the difficulties that arise on social, psychosocial and moral grounds. It should be mandatory of any AIDS prevention or control strategy to relate to the definitive and specific problems of women and ensure break of transmission. Promoting reproductive rights is critical for HIV prevention and women's empowerment, and for preventing poverty, maternal and child deaths and STI. With good reproductive health, women feel more in control of their lives, are more productive, and tend to have fewer and healthier children. Women need to be empowered to make decisions and take action to protect their reproductive and sexual health. If women gained control in this area, and had access to contraception and relevant services, their health status would dramatically improve, with far less maternal deaths, unplanned births and STI Measures that encourage equality, economic independence and education protect from HIV, mitigate the impact of AIDS and promote development [4].

\section{CONCLUSION :}

Despite reductions in prevalence of Human Immunodeficiency Virus (HIV) infection among the general population of India, women account for a rising percentage of all HIV cases with husband's risk behavior described as the major source of women's infection. Polygamy, sexual coercion and violence against women all contribute to this distressing fact. This imbalance reflects not only the heightened physiological vulnerability of girls and young women, but also a high prevalence

of intergenerational partnerships, the lack of woman - initiated prevention methods and broader social and legal inequality that impedes the ability of the women to reduce their sexual risk. It requires recognition that nondiscrimination, pragmatism and compassion will yield benefits not only for the HIV response but also across health, development and human rights priorities. There are various ways and means to prevent mother-to-child transmission at various stages. Some of these prevention methods are the protection of girls and women from HIV infection: HIV transmission can be minimized among women of childbearing age if they are provided adequate information on HIV/AIDS. This strategy is sometimes referred to as "primary prevention". It involves promoting abstinence before marriage, responsible sexual behaviour among couples, providing them with knowledge about HIV/AIDS and how to prevent infection and ensuring that they have the necessary personal skills and access to marital and sexual health counselling services so that they can act on their knowledge. It also means providing good quality, user-friendly prevention and treatment programmes for other sexually transmitted diseases (STDs). The gender inequality, socio-cultural norms about masculinity and femininity and power relations between men and women have been central to the spread of the HIV epidemic in India. Prevention, care, support and impact mitigation in HIV/AIDS can only be done successfully if gender issues are recognized and addressed in HIV/AIDS programmes. Transforming gender relations and reducing gender inequality through development work will not help reduce vulnerability to HIV infection but also strengthen the capacities of individual, household and communities to cope with the consequences of HIV/AIDS.

\section{REFERENCES:}

[1] D'Mello Laveena and Govindaraju B. M. (2013). A Study on Socio-Economic condition of HIV Positive people in Dakshina Kannada. ISBN 978-81922146-5-8.

[2] Gangakhedkar, R. Bentley, M. (1997). Spread of HIV infection in married monogamous women in India. Journal of American Medical Association, 278, 2090-2.

[3] Ramachandran T. (2008). Rural Women's Health- a Study in Rural Villages of 
Kanyakumari District. Social welfare, 55(1-2).

[4] Solomon, S. \& Buck, J. (2003): Stopping HIV before it begins: Issues faced by women in India. Nature Immunol, 4, 719721.

[5] Sujatha D. Sai (2011). Women and HIV. Associate Professor, Department of Population Studies \& Social Work, Sri Venkateswara, University. Social welfare, 58.

[6] Sujatha D. Sai, (2011). Women and HIV/AIDS, Social welfare, 58, (9).

[7] Sushma Gupta and Sood, O. P. (2000). HIV/AIDS in India. Proceedings of the Sixth Round Table Conference, New Delhi.

[8] Tayler Yolanda, (2004). Battling HIV/AIDS, decision maker's guide to the procurement of medicine and related supplies. The World Bank, Washington.

[9] UNAIDS/ UNFPA/UNIFEM (2005): "Women and HIV AIDS: Confronting the Crisis", A Joint Report

[10] UNGASS, (2010): United Nations General Assembly Special Session, Report.

[11] UNICEF, (2005); 'Accelerating the Momentum in the Fight Against HIV/AIDs in South Asia, overview paper.

[12] United Nations Children's Fund, (UNICEF) Regional Office for South Asia, Nepal. 